\title{
Tea Polyphenols Synergistic Enhancement of Antibacterial Effects of NaF on the Cultured Streptococcus Mutans
}

\author{
Shoei Yn Lin Shiau* and Chia Tze Kao \\ College of Oral Medicine, Chung Shan Medical University, Taiwan \\ Received: June 14, 2018; Published: July 03, 2018 \\ *Corresponding author: Shoei Yn Lin Shiau, School of Dentistry, College of Oral Medicine, Chung Shan Medical University, No.110, Sec1, Jianguo N. \\ Road, Taichung, Taiwan
}

\begin{abstract}
It is reported that about $95 \%$ of the populations in the world have dental caries. Although NaF is an effective anticariogenic agent and F- is the strongest electronegative ion, the abuse of $\mathrm{NaF}$ is not only harmful to human beings (dental fluorosis, hepatotoxicity, nephrotoxicity etc.) but also an ecosystem destroyer. It is urgent to explore a better anticariogenic agent for prevention and therapy of dental caries. In this study, we have comparatively studied the antibacterial effects of four different kinds of tea polyphenols on the cultured cariogenic Streptococcus mutans UA159. The results obtained showed that tea polyphenols are more potent than NaF in inhibiting the growth of UA159 which is based on the concentrations (mM) required for $50 \%$ inhibition. An important finding is that black tea polyphenol is not only by itself to inhibit the growth of UA159 but also synergistically enhanced this inhibitory effect of NaF. Furthermore, tea polyphenols were also much more potent than $\mathrm{NaF}$ in inhibiting $\alpha$-glucosidase activities of UA159. In conclusion, the antibacterial effects of tea polyphenols on the cultured anticariogenic Streptococcus mutans UA159. It is expected that tea polyphenols could be developed as promising anticariogenic agents in the future.
\end{abstract}

Keywords: Dental Caries; Streptococcus Mutans; NaF; Tea Polyphenols; Antibacterial Effects

\section{Introduction}

Dental caries is the most common disease in the dentistry. It is estimated that $95 \%$ of populations in the world have this disease $[1,2]$. Thus, its medical cost is enormous greater than those on cancer, cardiovascular diseases, diabetes etc. Although the etiology of dental caries is explored, it is very difficult to eradicate. It is urgent to explore a better regimen for prevention and therapy of dental caries. Streptococcus mutans is recognized as a cause of dental caries. It can degrade sugar into glucose which is polymerized into glucan $[3,4]$. Dental plaque containing $70 \%$ of $S$. mutans and glucan was performed on the enamel surface. S. mutans can secret organic acids, which destroyed enamel and eventually led to dental caries. The effective anticariogenic NaF not only possessed anti-bacterial effects but also altered enamel structure to synthesize aciduratic $\mathrm{CaFPO}_{4}$ [5-7]. However $\mathrm{F}^{-}$is the most electronegative ion, not only highly toxic to tissues and cells (fluorosis, hepatotoxicity and nephrotoxicity), but also destroying our ecosystems [8-11]. It is very important to develop a better anticariogenic agent to replace or reducing the consumption of $\mathrm{NaF}$ and its analogues.

Tea polyphenols such as green tea polyphenol (EGCG) has been demonstrated to be a potent anti-cariogenic agent [12-15]. However, there are four kinds of teas commonly used (unfermented green tea, half-fermented oolong tea, complete fermented black tea and post fermented Puerh tea). In our laboratory, we have demonstrated that both black tea and puerh tea are the best to modulate obesity and diabetes, and cancer chemoprevention [16-22]. Because there are still no reports on the comparative potencies of the anticariogenic effects of the teas, thus, in this study, we attempted to explore tea polyphenols either alone or in combination with $\mathrm{NaF}$ on the growth, acid secretion, biofilm formation and $\alpha$-glucosidase activities of the cultured S.mutaus UA159. We have demonstrated that the antibacterial effect of black tea polyphenols was not only the most potent antibacterial, but also exhibited synergistic inhibitory effect in combination with NaF on UA159.

\section{Materials and Methods}

\section{Preparation of Tea Polyphenols and NaF}

Four kinds of tea polyphenols were isolated from green tea, black tea, oolong tea and puerh tea respectively according to the methods as described previously. The contents of tea polyphenols were analyzed by HPLC. EGCG and NaF were purchased from Sigma-Aldrich Co. U.S.A.

\section{Effect on the Growth of UA159}

The cariogenic Streptococcus mutans UA159 was cultured in brain heart infusion (BHI) medium at $37 \pm 0.5^{\circ} \mathrm{C}$ in anaerobic chamber, $10 \% \mathrm{H}_{2}, 5 \% \mathrm{CO}_{2}$ and $85 \% \mathrm{~N}_{2}$, Forma Sci. Inc., Masietta, $\mathrm{OH}, \mathrm{USA}$ [23]. The bacterial cell growth was assessed by measuring 
the optical density at $600 \mathrm{~nm}$ wavelength (OD600) with ELISA microplate reader [23]. The concentration for $50 \%$ inhibition $\left(\mathrm{IC}_{50}\right)$ was calculated from the concentration-inhibition curve. The potencies of the inhibitory effects of the combination were estimated by the formula of combination index (CI) [24]:

$$
C I=\frac{\left(I C_{50}\right)_{\text {1incombination }}}{\left(I C_{50}\right)_{1 \text { Alone }}}+\frac{\left(I C_{50}\right)_{2 \text { incombination }}}{\left(I C_{50}\right)_{1 \text { Alone }}}
$$

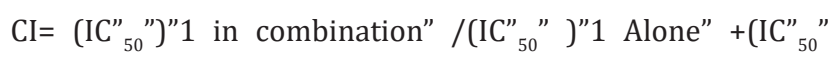
)"2 in combination" / $\left(\mathrm{IC}_{50}{ }_{50}\right)$ "1 Alone". Synergism, addition and antagonism in the combination were defined by the CI values $<1$, $=1$ or $>1$ respectively.

\section{Acid Secretion}

UA159 was cultured for $16 \mathrm{hrs}$ and then diluted with $0.004 \%$ bromocresol purple in $\mathrm{BHI}$ to $1.7 \times 10^{9} \mathrm{CFU} / \mathrm{ml}$. To a 96 well microplate, $180 \mu \mathrm{l}$ of diluted UA159 was added and mixed with $20 \mu$ l of tested solution( $\mathrm{NaF}$ and tea polyphenol either alone or in combination). Acid secretion of UA159 was monitored by the increases of $0 D 430 \mathrm{~nm}$ of $\mathrm{pH}$ indicator bromocresol purple after incubation at $37 \pm 0.5^{\circ} \mathrm{C}$ for $16 \mathrm{hrs}$. The inhibitory effects $\left(\mathrm{IC}_{50}\right.$ and combination index) of $\mathrm{NaF}$ and tea polyphenols either alone or in combination were estimated from the concentration-inhibition curve.

\section{Biofilm Formation}

The biofilm formation of UA159 on the 96 well microplate was carried out in $0.2 \%$ sucrose $-\mathrm{BHI}$ cultured medium at $37 \pm 0.5^{\circ} \mathrm{C}$ for $28 \mathrm{hrs}$ with $\mathrm{NaF}$ and tea polyphenol either alone or in combination $[15,25,26]$. The biofilm formation was quantitatively estimated by staining with $0.01 \%$ crystal violet at optical density $540 \mathrm{~nm}$. The inhibitory effects ( $\mathrm{IC}_{50}$ and combination index) of $\mathrm{NaF}$ and tea polyphenol either alone or in combination were estimated from the concentration-inhibition curve.

\section{$\alpha$-Glucosidase Activities}

The cultured UA159 was repetitively freeze-thawing three times and then homogenized by ultra-sonic treatment. For measurement of $\alpha$-glucosidase activities, the homogenate was optimally diluted with $0.1 \mathrm{M}$ PBS containing $2 \mathrm{mM} \mathrm{CaCl}$. To each well of 96-well microplate, $100 \mu \mathrm{l}$ of the diluted homogenate was mixed with $50 \mu \mathrm{l}$ of various concentrations of $\mathrm{NaF}$ and tea polyphenol either alone or in combination; the enzyme activity was initiated by addition of $50 \mu \mathrm{l}$ of $1.25 \mathrm{mM}$ p-nitrophenol- $\alpha$-D-glucopyranoside(PNPG) and then incubated at $37 \pm 0.5^{\circ} \mathrm{C}$ for $24 \mathrm{hrs}$ [27]. The increase of endproduct p-nitrophenol which was proportional to the enzymatic activities was measured by optical density at $405 \mathrm{~nm}$. IC $_{50}$ of the test compounds and their combination index were estimated as described above.

\section{Statistical Analysis}

The experimental data were expressed as mean \pm S.E.M. The significance of the difference between the tested groups and the control group was analyzed by one way of variance (ANOVA) and a post hoc t-test. $\mathrm{P}<0.05$ was regarded as statistical significance.

\section{Results}

\section{Antibacterial Effects of $\mathrm{NaF}$ and Tea Polyphenols on UA159}

As shown on (Figures 1 \& 2), NaF and tea polyphenols were effectively in the inhibition of growth, acid secretion, biofilm formation and $\alpha$-glucosidase of S.mutans in a concentrationdependent manner. The concentration for $50 \%$ inhibition $\left(\mathrm{IC}_{50}\right)$ were obtained from Figure. 1 and listed on Table 1. From $\mathrm{IC}_{50}$ values, it was shown that the order of the potencies of growth inhibition by four kinds of tea polyphenols was as following: TF50 $>0$ TP $>$ GTP $>$ Puerh>EGCG. It is noted that if $\mathrm{IC}_{50}$ was expressed in $\mathrm{mM}$ instead of $\mathrm{mg} / \mathrm{ml}$, the results showed that EGCG and OTP were about two and four times respectively more potent than NaF and TF50 was the most potent, about 17 times greater than NaF.The cultured medium containing $0.2 \%$ sucrose had little effect on NaF but reduced the inhibitory effect of tea polyphenols on the growth of UA159 (Table 1). Similarly, tea polyphenols also inhibited the acid secretion and biofilm formation of UA159. By contrast, four tea polyphenols except Puerh tea polyphenol were much more potent than $\mathrm{NaF}$ in inhibiting the $\alpha$-glucosidase activities of UA159 homogenate (Figure 2) and (Table 1).

Table 1: Antibacterial effects of NaF and tea polyphenols on the cultured UA159.

\begin{tabular}{|c|c|c|c|c|c|c|}
\hline \multicolumn{7}{|c|}{ IC $_{50}$ (mg/ml) } \\
\hline Inhibitory effect & NaF & EGCG & GTP & OTP & TF50 & Puerh \\
\hline Growth without $0.2 \%$ sucrose & $\begin{array}{c}0.03 \pm 0.001(0.7 \\
\mathrm{mM})\end{array}$ & $\begin{array}{c}0.16 \pm 0.004(0.35 \\
\mathrm{mM})\end{array}$ & $0.14 \pm 0.001$ & $\begin{array}{c}0.13 \pm 0.002(0.15 \\
\mathrm{mM})\end{array}$ & $\begin{array}{c}0.06 \pm 0.01(0.04 \\
\mathrm{mM})\end{array}$ & $0.14 \pm 0.02$ \\
\hline Growth with 0.2\% sucrose & $0.02 \pm 0.003$ & $0.23 \pm 0.03$ & $0.29 \pm 0.02$ & $0.53 \pm 0.13$ & $0.67 \pm 0.16$ & $0.87 \pm 0.29$ \\
\hline Acid secretion & $0.03 \pm 0.002$ & $0.23 \pm 0.02$ & $0.17 \pm 0.003$ & $0.13 \pm 0.01$ & $0.06 \pm 0.01$ & $0.33 \pm 0.13$ \\
\hline Biofilm formation & $0.04 \pm 0.002$ & $0.24 \pm 0.10$ & $0.15 \pm 0.01$ & $0.15 \pm 0.03$ & $0.28 \pm 0.01$ & $0.94 \pm 0.08$ \\
\hline$\alpha$-Glucosidase $\mathrm{IC}_{50}(\mu \mathrm{g} / \mathrm{ml})$ & $4.81 \pm 0.15$ & $0.76 \pm 0.08$ & $1.94 \pm 0.23$ & $4.91 \pm 0.87$ & $1.13 \pm 0.23$ & $46.49 \pm 1.20$ \\
\hline
\end{tabular}

\section{a. UA159: Streptococcus mutans}

b. $\quad \mathrm{IC}_{50}$ : Concentration for $50 \%$ inhibition.

c. TP, tea polyphenol; EGCG, epigallocatechin gallate; GTP, green tea polyphenol; OTP, oolong tea polyphenol, TF50, black tea polyphenol; Puerh, puerh tea polyphenol 
A.

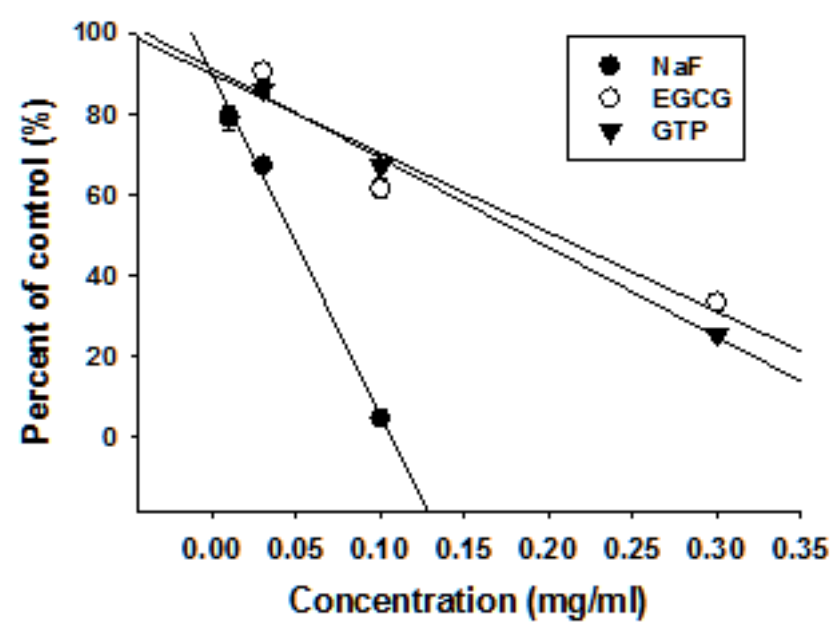

C.

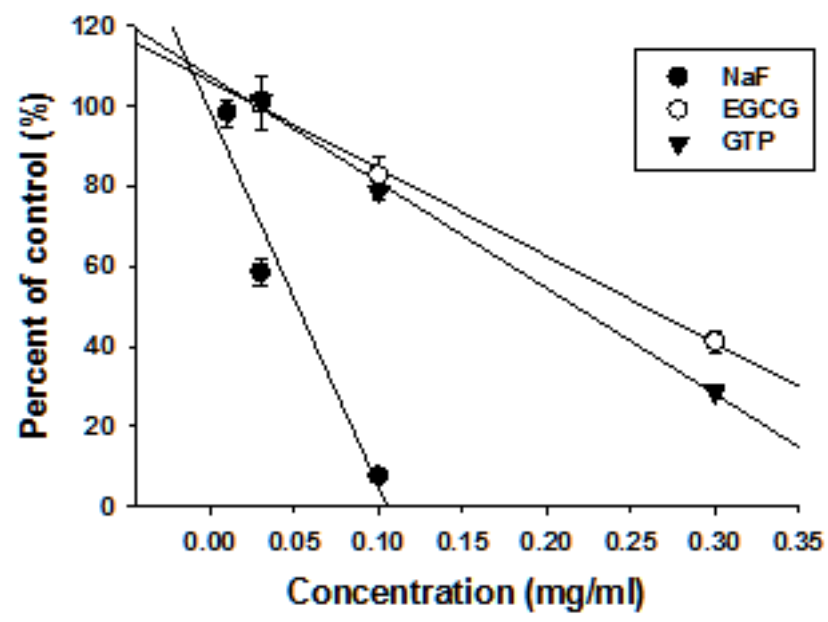

E.

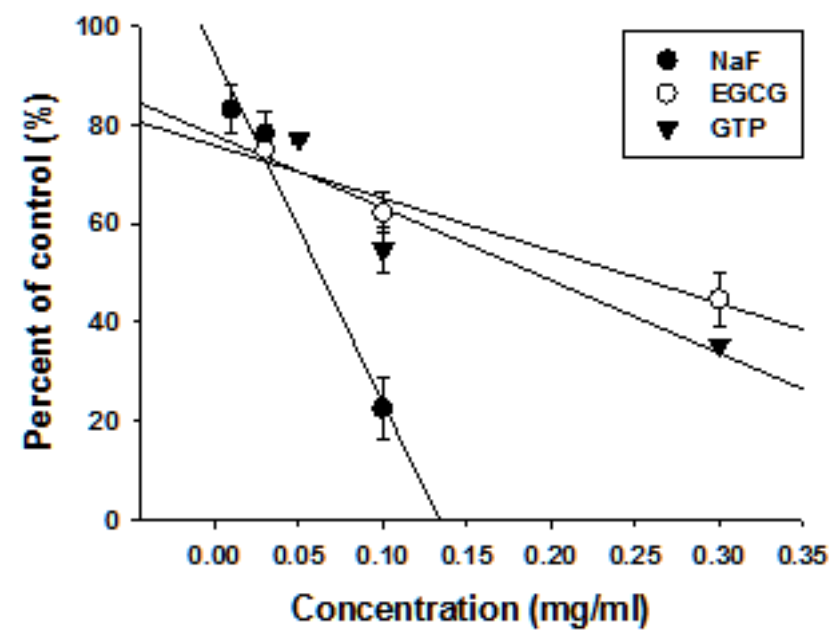

B.

D.

F.
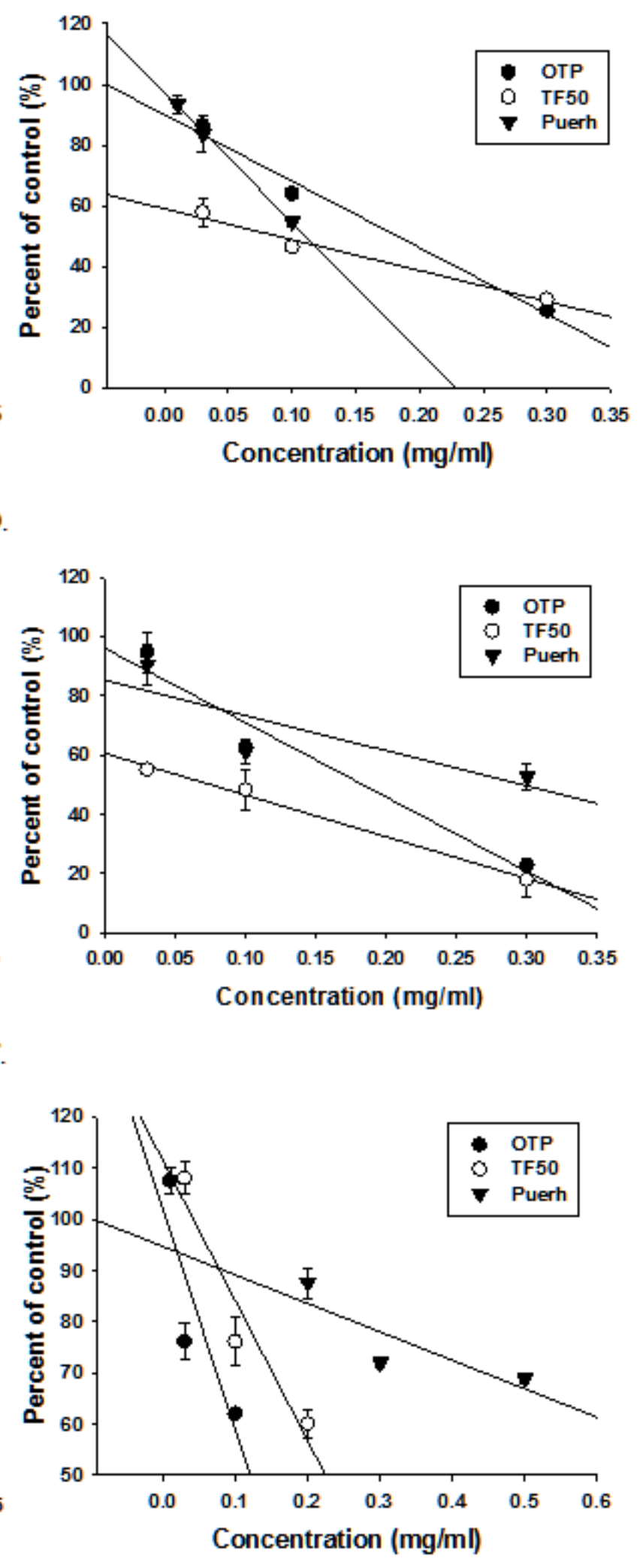

Figure 1: Concentration-inhibition curve of $\mathrm{NaF}$ and tea polyphenols alone on the growth $(\mathrm{A}, \mathrm{B})$, acid secretion $(\mathrm{C}, \mathrm{D})$ and biofilm formation (E, F) of Streptococcus mutans UA159. 

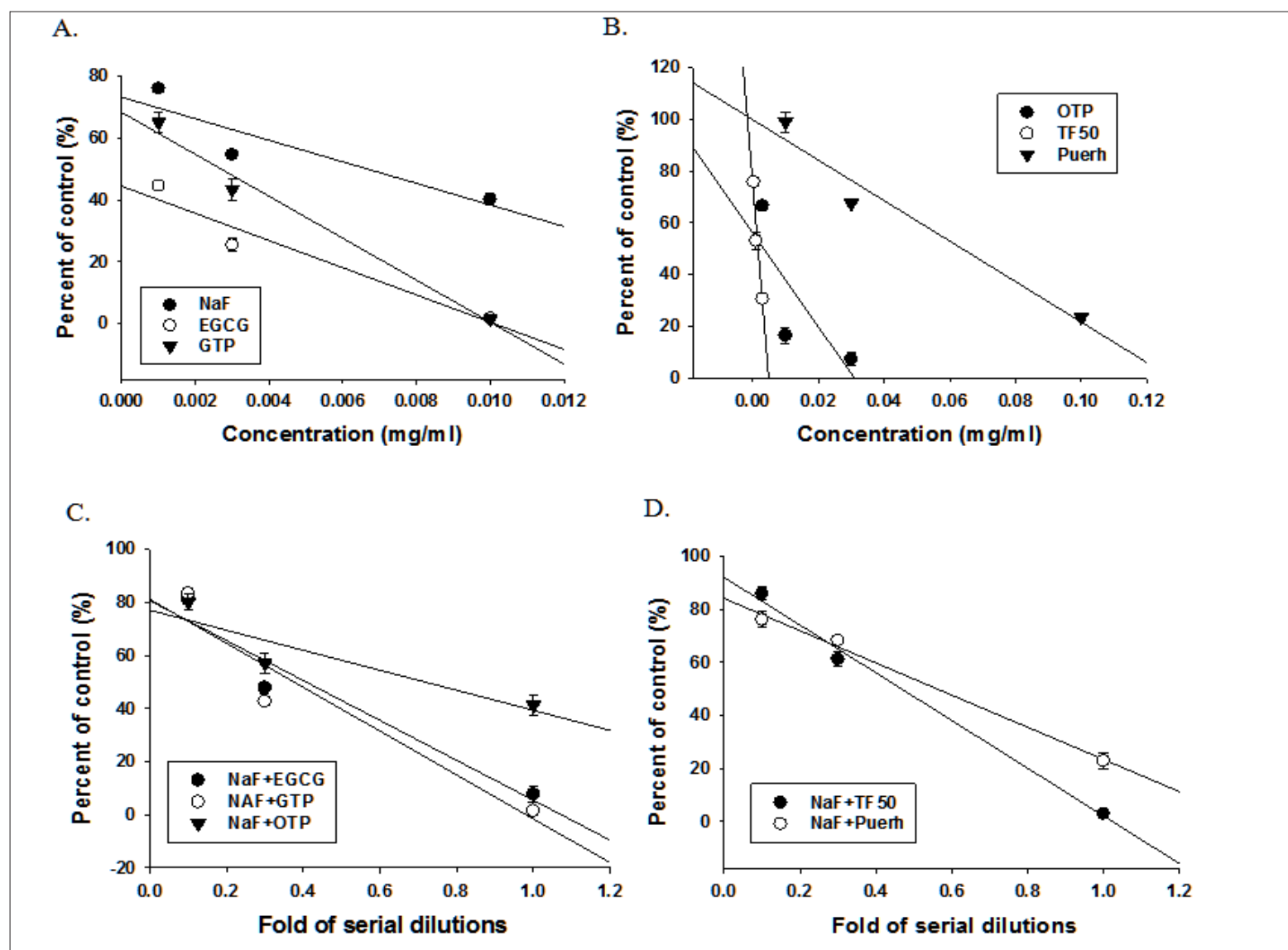

Figure 2: Concentration-inhibition curve of $\mathrm{NaF}$ and tea polyphenols either alone $(\mathrm{A}, \mathrm{B})$ or in combination $(\mathrm{C}$, $\mathrm{D})$ on a-glucosidase activities of Streptococcus mutans UA159.

\section{Antibacterial Effects of the Drug Combinations on UA159.}

As shown on Figures $2 \& 3$, the inhibitory effects of $\mathrm{NaF}$ combined with tea polyphenols on the growth, acid secretion, biofilm formation and $\alpha$-glucosidase activities of UA159 were in concentration dependent manner and the calculated concentrations for $50 \%$ inhibition $\left(\mathrm{IC}_{50}\right.$ ) were listed on Table 2.
The tea polyphenols such as EGCG and TF50 were synergistically enhanced NaF in inhibiting the growth of UA159 as revealed by the combination index (CI) less than 1.0 (Table 2). However, these drugs combinations exhibited either addition or mild antagonism with each other in the inhibitory effects on acid secretion, biofilm formation and $\alpha$-glucosidase activities, with an exception that OTP synergistically enhanced $\mathrm{NaF}$ in inhibiting acid secretion and $\alpha$-glucosidase activities

Table 2: Antibacterial effects of NaF and combination with tea polyphenols on UA159.

\begin{tabular}{|c|c|c|c|c|c|c|}
\hline \multicolumn{7}{|c|}{$\mathrm{IC}_{50}(\mathrm{mg} / \mathrm{ml})$} \\
\hline Inhibitory effect & & $\mathrm{NaF}+\mathrm{EGCG}$ & $\mathrm{NaF}+\mathrm{GTP}$ & $\mathrm{NaF}+\mathrm{OTP}$ & $\mathrm{NaF}+\mathrm{TF} 50$ & $\mathrm{NaF}+$ Puerh \\
\hline \multirow{3}{*}{$\begin{array}{l}\text { Growth without } \\
0.2 \% \text { sucrose }\end{array}$} & $\mathrm{NaF}$ & $0.020 \pm 0.001$ & $0.030 \pm 0.005$ & $0.026 \pm 0.004$ & $0.013 \pm 0.002$ & $0.027 \pm 0.002$ \\
\hline & $\mathrm{TP}$ & $0.041 \pm 0.002$ & $0.061 \pm 0.006$ & $0.053 \pm 0.004$ & $0.026 \pm 0.004$ & $0.054 \pm 0.018$ \\
\hline & $\mathrm{CI}$ & 0.92 & 1.44 & 1.27 & 0.87 & 1.29 \\
\hline \multirow{3}{*}{$\begin{array}{l}\text { Growth with } 0.2 \% \\
\text { sucrose }\end{array}$} & $\mathrm{NaF}$ & $0.062 \pm 0.002$ & $0.033 \pm 0.002$ & $0.044 \pm 0.001$ & $0.066 \pm 0.001$ & $0.034 \pm 0.011$ \\
\hline & $\mathrm{TP}$ & $0.153 \pm 0.037$ & $0.080 \pm 0.017$ & $0.087 \pm 0.001$ & $0.132 \pm 0.002$ & $0.067 \pm 0.021$ \\
\hline & $\mathrm{CI}$ & 3.77 & 1.93 & 2.36 & 3.50 & 1.78 \\
\hline \multirow{3}{*}{ Acid secretion } & $\mathrm{NaF}$ & $0.035 \pm 0.004$ & $0.038 \pm 0.007$ & $0.023 \pm 0.011$ & $0.028 \pm 0.005$ & $0.044 \pm 0.003$ \\
\hline & $\mathrm{TP}$ & $0.070 \pm 0.008$ & $0.076 \pm 0.008$ & $0.046 \pm 0.008$ & $0.056 \pm 0.001$ & $0.087 \pm 0.025$ \\
\hline & $\mathrm{CI}$ & 1.47 & 1.71 & 1.12 & 1.87 & 1.73 \\
\hline \multirow{3}{*}{ Biofilm formation } & $\mathrm{NaF}$ & $0.087 \pm 0.005$ & $0.124 \pm 0.047$ & $0.334 \pm 0.039$ & $0.069 \pm 0.082$ & $0.105 \pm 0.039$ \\
\hline & $\mathrm{TP}$ & $0.173 \pm 0.039$ & $0.248 \pm 0.005$ & $0.668 \pm 0.054$ & $0.137 \pm 0.164$ & $0.209 \pm 0.109$ \\
\hline & CI & 2.90 & 4.75 & 12.80 & 2.21 & 2.85 \\
\hline
\end{tabular}




\begin{tabular}{|c|c|c|c|c|c|c|}
\hline \multirow{2}{*}{$\begin{array}{c}\alpha-G l u c o s i d a s e ~ I C \\
50\end{array}(\mu \mathrm{g} / \mathrm{ml})$} & $\mathrm{NaF}$ & $2.50 \pm 0$ & $2.50 \pm 0$ & $0.50 \pm 0$ & $0.50 \pm 0$ & $2.50 \pm 0$ \\
\cline { 2 - 7 } & $\mathrm{TP}$ & $0.52 \pm 0.15$ & $1.22 \pm 0.27$ & $4.68 \pm 1.28$ & $1.01 \pm 0.23$ & $54.47 \pm 23.42$ \\
\cline { 2 - 7 } & $\mathrm{CI}$ & 1.20 & 1.15 & 1.06 & 1.00 & 1.69 \\
\hline
\end{tabular}

\section{a. UA159: Streptococcus mutans}

b. $\quad \mathrm{IC}_{50}$ : Concentration for $50 \%$ inhibition.

c. TP, tea polyphenol; EGCG, epigallocatechin gallate; GTP,green tea polyphenol; OTP, oolong tea polyphenol, TF50,black tea polyphenol; Puerh, puerh tea polyphenol.

d. $\quad$ CI: Combination index.
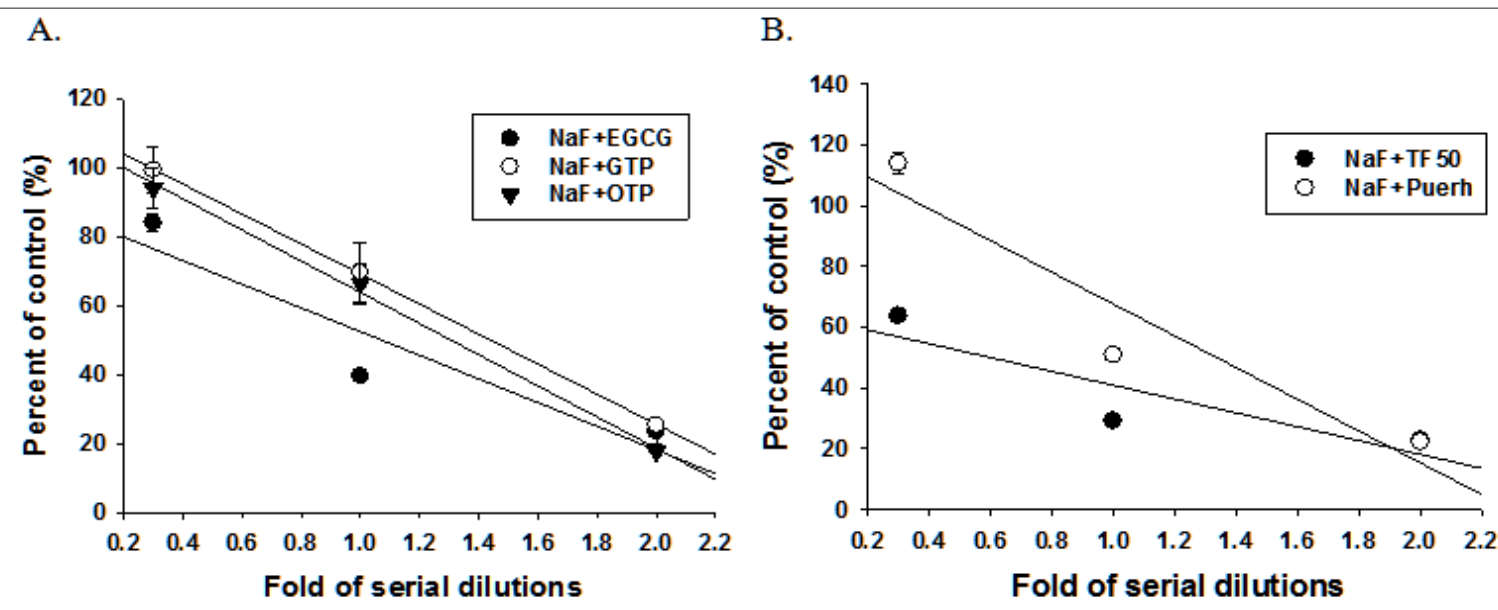

C.

D.
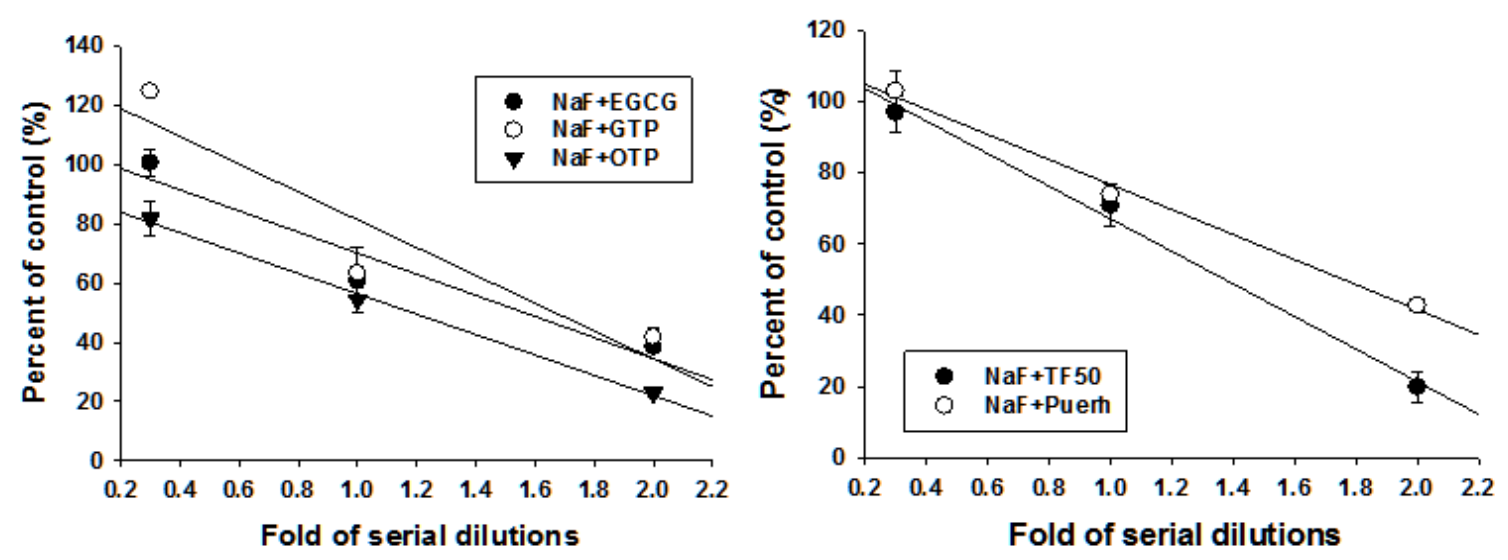

E.

F.
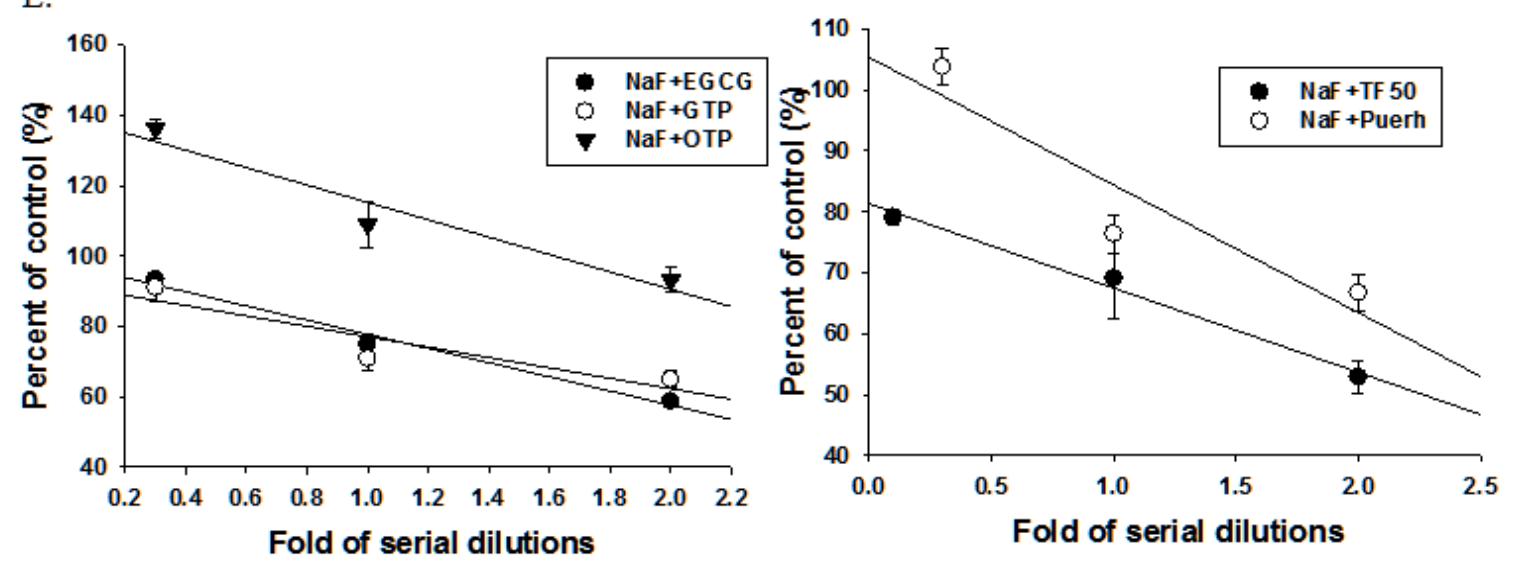

Figure 3: Concentration-inhibition curve of $\mathrm{NaF}$ and tea polyphenols in combination on the growth $(\mathrm{A}, \mathrm{B})$, acid secretion $(\mathrm{C}$, D) and biofilm formation (E, F) of Streptococcus mutans UA159. 


\section{Discussion}

Streptococcus mutans is a major cause of dental caries, which can form dental plaque on the enamel surface and secrets organic acid to induce enamel dermineralization, leading to dental caries [1-3]. NaF is indeed a very effective anticariogenic agent, not only inhibits the growth of S.mutans but also inhibit acid secretion and biofilm formation [5,6]. Because of the highly toxic effects on human tissues and also destruction of our ecosystem [7-11], we need to search for another effective anticariogenic agents.Recently, it is getting popular to search naturally occurring anticariogenic agents such as curcumin [28-30], probiotics [31]. We considered that tea polyphenols possessing the pleiotropic biological effects would be the ideal anticariogenic agents. Thus, we attempted to study the various kinds of tea polyphenols either alone or in combination with $\mathrm{NaF}$ on antibacterial effects of $S$. mutans which has not been reported yet.

Tea is the most popular beverage in the world. The health effects of tea polyphenols (antioxidant, anti-inflammatory, cancer chemoprevention, antiobesity, antidiabetic and neuroprotection etc.) have well been studied [16-22]. We have demonstrated that black tea and Puerh tea are the best, oolong tea is next and green tea is the least in hypolipidemic and antiobesity effects. Green tea polyphenol EGCG has been well studied in anticariogenic effects [15]. In this study, we have found that black tea polyphenol is better than EGCG in inhibiting the growth of cariogenic $S$. mutans UA159 especially the synergistic effect of black tea polyphenol in combination with $\mathrm{NaF}$ in the inhibition of bacterial growth. This finding is apparently in accordance with the content that antibacterial effects of tea polyphenols are mediated by its destructive effects on the cell membrane. Puerh tea is perhaps the best to modulate the cell metabolism rather than on altered effects on the cell membrane.

\section{Conclusion}

In conclusion, we have found in this study that all of the tea polyphenols exhibited more potent than $\mathrm{NaF}$ in inhibiting the growth of cariogenic Streptococcus mutans UA159 (as estimated in molar concentrations). Among them, black tea polyphenols were not only the most potent but also synergistically enhanced $\mathrm{NaF}$ in this effect. It is expected that black tea polyphenols would be the promising anticariogenic agent in the future.

\section{Acknowledgement}

The authors greatly appreciate the former dean Professor Ming young Chou for his continuous support of this research. It is indebted to the late Academician Professor Jen-Kun Lin for his enthusiastic encouragements in the studies of tea polyphenols. Thanks to the excellent technical assistance of Miss Yi-An Chen. This research was supported by a grant from CSMU F0130004.

\section{References}

1. Bánóczy J, Rugg Gunn A (2013) Epidemiology and prevention of dental caries. Acta Med Acad 42(2): 105-107.

2. Rugg Gunn A (2013) Dental caries: strategies to control this preventable disease. Acta Med Acad 42(2): 117-130.
3. Schüler V, Lussi A, Kage A, Seemann R (2012) Glycan-binding specificities of Streptococcus mutans and Streptococcus sobrinus lectin-like adhesins. Clin Oral Investig 16(3): 789-796.

4. Gregoire S, Xiao J, Silva BB, Gonzalez I, Agidi PS, et al. (2011) Role of glucosyltransferase B in interactions of Candida albicans with Streptococcus mutans and with an experimental pellicle on hydroxyapatite surface. Appl Environ Microbiol 77(18): 6357-6367.

5. Carey CM(2014)Focus on fluorides: update on the use of fluoride for the prevention of dental caries. J Evid Based Dent Pract 14 Suppl: 95-102.

6. Máiread Antoinette Harding, Denis Martin O`Mullane (2013) Water fluoridation and oral health. Acta MedicaAcademica 42(2): 131-139.

7. Chau NP, Pandit S, Jung JE, Jeon JG (2014) Evaluation of Streptococcus mutans adhesion to fluoride varnishes and subsequent change in biofilm accumulation and acidogenicity. J Dent 42(6): 726-734.

8. (2013) Centers for Disease Control and Prevention. Community Water Fluoridation,Images of Fluorosis, Dental Fluorosis FAQs, USA.

9. Bartlett JD, Dwyer SE, Beniash E, Skobe Z, PayneFerreira TL(2005) Fluorosis: a new model and new insights.J Dent Res84(9):832-836.

10. Perumal E, Paul V, Govindarajan V, Panneerselvam L (2013) A brief review on experimental fluorosis. Toxicol Lett 223(2): 236-251.

11. Pearcy K, Elphick J, Burnett Seidel C (2015) Toxicity of fluoride to aquatic species and evaluation of toxicity modifying factors. Environ Toxicol Chem 34(7): 1642-1648.

12. Ferrazzano GF, Roberto L, Amato I, Cantile T, Sangianantoni G, et al. (2011) an in Antimicrobial properties of green tea extract against cariogenic microflora vivo study. J Med Food 14(9): 907-911.

13. Otake S, Markimura M, Kuroki T, Nishihara Y, Hirasa M(1991) Anticaries effects of polyphenolic compounds from Japanese green tea. Caries Res 25(6): 438-443.

14. Hattori M, Kusumoto IT, Namba T, Ishigami T, Hara Y(1990) Effects of tea polyphenols on glucan synthesis by glucosytransferase from Streptococcus mutans. ChemPharmBull 38(3): 717-720.

15. Xin Xu, Xue, DZhou, Christine DWu (2012) Tea catechin epigallocatechin gallate inhibits Streptococcus mutans biofilm formation by suppressing gtf genes. ArchOral Bio 157: 678-683.

16. LinJK, LinCL, LiangYC, LinShiau SY, Juan IM (1998) Survery of catechins gallic acid and methylxanthine in green,oolong, pu-erh and black teas. J Argic Food Chem 46: 3635-3642.

17. Lin YL, JuanIM, ChenYL, Liang YC, Lin JK (1996)Compositionof polyphenols in fresh tea leaves and association of their oxygen radicalabsorbing capacity with antiproliferative actions in fibroblast cells. J Argic Food Chem 44: 1387-1394.

18. Lin JK, LiangYC (2000) Cancer chemoprevention by tea polyphenols (an Invited Review Article) ProcNatl SciCounc (B) Biol Sci 24(1): 1-13.

19. LinJK, LiangYC, LinShiau SY(1999)Cancer chemoprevention by tea polyphenols through mitotic signal blockade (a Commentary) Biochem. Pharmacol 58: 911-915.

20. Cai EP, Lin JK (2009) Epigallocatechin gallate (EGCG) and rutin suppress the glucotoxicity through activating IRS2 and AMPK signaling in rat pancreatic beta cells. J AgricFood Chem 57(20): 9817-9827.

21. Lin CL, Huang HC, Lin JK (2007) The aflavins attenuate hepactic lipid accumulation through activating AMPK in human HepG2 cells. J Lipid Res 48(11): 2334-2343.

22. Huang HC, Lin JK (2012) Pu-erh tea, green tea, and black tea suppresses hyperlipidemia, hyperleptinemia and fatty acid synthase through activating AMPK in rats fed a high-fructose diet. Food Funct 3: 170-177.

23. Tong Z, Zhou L, Jiang W, Kuang R, Li J, et al. (2011) An in vitro synergetic evaluation of the use of nisin and sodium fluoride or chlorhexidine against Streptococcus mutans. Peptides 32(10): 2021-2026. 
24. Chou TC (2010) Drug combination studies and their synergy quantification using the Chou-Talalay method. Cancer research 70(2) 440-446.

25. Peeters E, Nelis HJ, Coenye T (2008) Comparison of multiple methods for quantification of microbial biofilms grown in microtiter plates. Journal of microbiological methods 72(2): 157-165.

26. LiX, YanZ, Xu J (2003) Quantitative variation of biofilms among strains in natural populations of Candida albicans. Microbiology 149(2): 353-362.

27. Deng YT, LinShiau SY, Shyur LF, Lin JK (2015) Pu-erh tea polysaccharides decrease blood sugar by inhibition of $\alpha$-glucosidase activity in vitro and in mice. Food \& function 6(5): 1539-1546.

28. Li B, Li X, Lin H, Zhou Y (2018) Curcumin as a Promising Antibacterial Agent: Effects on Metabolism and Biofilm Formation in SmutansBiomed Res Int 4508709 .

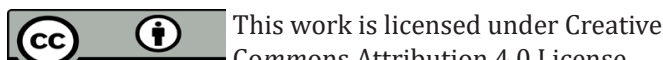

Submission Link: https://biomedres.us/submit-manuscript.php
29. Lee HJ, Kang SM, Jeong SH, Chung KH, Kim BI (2017) Antibacterial photodynamic therapy with curcumin and Curcuma xanthorrhiza extract against Streptococcus mutans. Photodiagnosis Photodyn Ther 20: 116-119.

30. Maghsoudi A, Yazdian F, Shahmoradi S, Ghaderi L, Hemati M, et al. (2017) Curcumin-loaded polysaccharide nanoparticles: Optimization and anticariogenic activity against Streptococcus mutans. Mater Sci Eng C Mater Biol Appl 75: 1259-1267.

31. Lee SH, Kim YJ(2014) A comparative study of the effect of probiotics on cariogenic biofilm model for preventing dental caries.Arch Microbiol 96(8): 601-609.

Assets of Publishing with us
BIOMEDICAL
RESERCHES $\quad \begin{aligned} & \text { Global archiving of articles } \\ & \text { - Immediate, unrestricted online access } \\ & \text { - Rigorous Peer Review Process } \\ & \text { - Authors Retain Copyrights }\end{aligned}$

